\title{
Predictores clínicos de eventos adversos serios en el adulto inmunocompetente hospitalizado por neumonía adquirida en la comunidad
}

\author{
FERNANDO SALDÍAS P.*, JAVIER URIBE M.**, JAVIERA GASSMANN P.**, \\ ALEJANDRO CANELO L.** y ORLANDO DÍAZ P.*
}

\begin{abstract}
Clinical predictors of serious adverse events in immunocompetent adult patients hospitalized with community-acquired pneumonia
\end{abstract}

Introduction: Community-acquired pneumonia (CAP) causes significant morbidity and mortality in adult population. Objectives: To assess clinical and laboratory variables measured at hospital admission associated to clinically relevant adverse outcomes in patients hospitalized with communityacquired pneumonia. Methods: We prospectively assessed clinical and laboratory variables associated to serious adverse events in a cohort of CAP hospitalized adult patients. Major adverse outcomes were admission to ICU, need for mechanical ventilation, septic shock, prolonged hospital stay, cardiovascular and in-hospital complications and 30-day mortality. The clinical and laboratory variables measured at hospital admission associated to serious adverse events were assessed by univariate and multivariate analysis using logistic regression models. Results: 659 CAP hospitalized immunocompetent adult patients were assessed, mean age: 67 years, 52\% were male, 77\% had comorbidities, 23\% were admitted to the intensive care unit (ICU), 12\% needed mechanical ventilation, $31 \%$ had hospital complication, mean hospital length of stay was 9 days and 9.9\% died at 30-days follow up. Comorbidities, hemodynamic instability and renal dysfunction were associated with ICU admission, risk of complications, and prolonged hospital stay. Mechanical ventilation requirement and septic shock were more frequent in patients with hemodynamic instability and renal dysfunction. Advanced age, chronic cardiovascular and respiratory diseases, aspiration pneumonia, tachypnea, and renal dysfunction were associated with high risk of cardiovascular events in the hospital. Conclusion: The clinical and laboratory variables measured at hospital admission allow us to predict the risk of serious adverse events in CAP hospitalized adult patients.

Key words: Community-acquired infections; pneumonia; intensive care units; logistic model; aged; comorbidity; shock, septic; tachypnea.

\section{Resumen}

Introducción: La neumonía adquirida en la comunidad (NAC) ocasiona morbilidad y mortalidad significativa en la población adulta. Objetivos: Examinar las variables clínicas y de laboratorio medidas en la admisión al hospital que permiten predecir los eventos adversos clínicamente relevantes en pacientes adultos hospitalizados por neumonía comunitaria. Métodos: Evaluamos las variables clínicas y de laboratorio asociadas a eventos adversos serios en una cohorte de adultos hospitalizados por NAC. Los eventos adversos examinados fueron la admisión a UCI, necesidad de ventilación mecánica, shock séptico, complicaciones cardiovasculares y generales y estadía prolongada en el hospital y mortalidad a 30 días. Las variables predictoras fueron sometidas a análisis univariado y multivariado en un modelo de regresión logística. Resultados: Se evaluaron 659 pacientes, edad: $67 \pm 18$ años,

Fuente de financiamiento: Proyecto Interdepartamental de la Facultad de Medicina, Pontificia Universidad Católica de Chile.

* Departamento de Enfermedades Respiratorias, División de Medicina, Facultad de Medicina, Pontificia Universidad Católica de Chile, Santiago, Chile.

** Alumnos de Medicina, Facultad de Medicina, Pontificia Universidad Católica de Chile. 
$52 \%$ varones, $77 \%$ tenía comorbilidad, $23 \%$ fueron admitidos a la UCI, $12 \%$ requirieron ventilación mecánica, 31\% presentaron complicaciones en el hospital, la estadía media en el hospital fue 9 días y 9,9\% fallecieron en el seguimiento a 30 días. Las comorbilidades, inestabilidad hemodinámica y disfunción renal se asociaron con la admisión a UCI, riesgo de complicaciones y estadía prolongada en el hospital. El uso de ventilación mecánica y shock séptico fue más frecuente en pacientes con inestabilidad hemodinámica y disfunción renal. La edad avanzada, enfermedades cardiovasculares y respiratorias crónicas, sospecha de aspiración, taquipnea y disfunción renal se asociaron al riesgo de eventos cardiovasculares en el hospital. Conclusión: Las variables clínicas y de laboratorio medidas en la admisión al hospital permiten predecir el riesgo de eventos adversos serios en el adulto hospitalizado por neumonía.

Palabras clave: Infecciones adquiridas en la comunidad; neumonía; unidades de cuidados intensivos; modelo logístico; edad avanzada; comorbilidad; shock, séptico; taquipnea.

\section{Introducción}

La neumonía adquirida en la comunidad (NAC) es la principal causa de muerte de etiología infecciosa en el mundo, ocasiona 3-4 millones de muertes cada año, siendo la cuarta causa específica de muerte, con una incidencia estimada de $10-16$ casos por 1.000 habitantes $^{1-5}$. La mayoría de los pacientes con neumonía pueden ser manejados en el ámbito ambulatorio con un bajo riesgo de complicaciones y secuelas; se estima que 20 a $30 \%$ de los pacientes con neumonía requieren hospitalización debido a la gravedad de su condición ${ }^{6}$. La mortalidad de la neumonía fluctúa entre 5 y $10 \%$ y aumenta significativamente en el paciente hospitalizado, en el niño menor de un año, adulto mayor con comorbilidad múltiple y el huésped inmunocomprometido ${ }^{6,7}$. La incidencia, riesgo de complicaciones y muerte por neumonía varía en la población ${ }^{1-7}$, dependiendo de la edad, estado inmune, comorbilidades, agente causal, gravedad y extensión de la infección pulmonar, accesibilidad a los servicios de salud y grado de adherencia al tratamiento recomendado en las guías clínicas $^{8-10}$. En Chile, la neumonía es la séptima causa de muerte en la población, especialmente en el niño menor de un año y adulto mayor de 65 años con enfermedades preexistentes, con una tasa de mortalidad de 18 casos por 100.000 habitantes ${ }^{11}$.

La evaluación de la gravedad del paciente con neumonía permite predecir la evolución, estimar el riesgo de complicaciones y muerte, definir el lugar de manejo (ambulatorio o en el hospital), la extensión del estudio microbiológico y de laboratorio complementario, planificar el tratamiento antimicrobiano empírico, la ruta de administración y su duración ${ }^{6,7}$. Las guías clínicas nacionales e internacionales recomiendan evaluar la gravedad del paciente con neumonía considerando variables socio-demográficas, de la historia clínica y examen físico, hallazgos de la radiografía de tórax y de los exámenes de laboratorio solicitados en la admisión al hospital ${ }^{12-15}$. Se han elaborado varios índices pronósticos para facilitar este proceso, tales como el índice de gravedad de la neumonía (pneumonia severity index-PSI) descrito por Fine y cols ${ }^{16}$, el índice pronóstico propuesto por la Sociedad Británica de Tórax (CURB-65) ${ }^{17}$ y los índices predictores de neumonía comunitaria severa: SMART-COP ${ }^{18}$ y SCAP ${ }^{19}$.

Los clínicos tienden a sobreestimar o a subestimar la gravedad de los pacientes con neumonía atendidos en los servicio de atención primaria ${ }^{20-23}$. La evaluación de la gravedad basada en elementos clínicos objetivos permite reducir la tasa de hospitalización de pacientes de bajo riesgo, disminuyendo los costos sanitarios y el riesgo de eventos adversos asociados a la estadía en el hospital, e identificar a los pacientes de alto riesgo que deben ser manejados en el hospital, en sala de cuidados generales o unidades de cuidado crítico, optimizando el uso de los recursos sanitarios y reduciendo los riesgos de los pacientes inestables o de riesgo elevado ${ }^{6,7}$.

El propósito de este estudio es examinar las variables clínicas y de laboratorio medidas en la admisión al hospital asociadas a la pesquisa de eventos adversos serios (admisión a unidad de cuidados intensivos: UCI, uso de ventilación mecánica, shock séptico, estadía prolongada, complicaciones y mortalidad) en una cohorte de pacientes adultos inmunocompetentes hospitalizados por neumonía adquirida en la comunidad.

\section{Pacientes y Método}

Estudio clínico descriptivo prospectivo, se evaluaron 659 pacientes adultos inmunocompetentes hospitalizados por neumonía adquirida en la comunidad en el Hospital Clínico de la Pontificia Universidad Católica de Chile entre el 
$1^{\circ}$ de enero de 2013 y 31 de diciembre de 2015 . Los pacientes tenían 18 años de edad o más y cumplían los criterios diagnósticos de neumonía propuestos por Fang y $\operatorname{cols}^{24}$. Se excluyó del estudio a los pacientes menores de 18 años, a los pacientes hospitalizados durante el mes previo al ingreso o institucionalizados y a aquellos que tenían alguno de los siguientes criterios de inmunosupresión: infección por VIH, neoplasia activa, neutropenia (menor de 1.000 células $/ \mathrm{mm}^{3}$ ), tratamiento quimioterápico o inmunosupresor en los seis meses previos a la admisión y uso $\geq 20 \mathrm{mg} /$ día de prednisona o su equivalente durante los últimos tres meses. Los investigadores no estuvieron involucrados en el manejo de los pacientes y el estudio fue aprobado por el Comité de Ética en Investigación de la Institución.

En la admisión al hospital se consignaron las características sociodemográficas, comorbilidades, cuadro clínico y exámenes de laboratorio que permitieron estimar el riesgo de complicaciones y muerte en el paciente adulto hospitalizado por neumonía comunitaria ${ }^{6,7}$, incluyendo la medición de los índices pronósticos: PSI, CURB-65, SMART-COP y SCAP ${ }^{16-19}$. La descripción de la radiografía de tórax fue realizada por un radiólogo del Departamento de Radiología, quien desconocía el cuadro clínico de los pacientes. El patrón radiográfico se clasificó como: a) imagen de relleno alveolar; b) patrón intersticial y c) patrón mixto. Además se precisó el grado de extensión del compromiso radiográfico en: a) unilobar; b) multilobar ( $\geq 2$ lóbulos) o c) bilateral. Se registró la presencia de derrame pleural, absceso y cavitación.

Durante la hospitalización se consignaron las siguientes variables: tratamiento antimicrobiano empírico, admisión a UCI y conexión a ventilador mecánico, estadía en el hospital y desarrollo de las siguientes complicaciones: insuficiencia respiratoria grave $\left(\mathrm{PaO}_{2} / \mathrm{FiO}_{2}<200\right)$; síndrome de distrés respiratorio agudo; accidente vascular encefálico; insuficiencia renal aguda (aumento de la creatinina sérica mayor de 3 veces el valor basal, creatinina sérica mayor de $4 \mathrm{mg} / \mathrm{dL}$ o que requiere diálisis); shock séptico (paciente con hipotensión arterial persistente que no responde a fluidos y que requirió uso de fármacos vasopresores); empiema pleural e infección extra-pulmonar. Se definió que un paciente tenía una complicación cardiovascular si en algún momento de la evolución presentaba arritmias (taquicardia paroxística supraventricular, flutter, fibrilación auricular, taquicardia ventricular), insuficiencia cardíaca congestiva, isquemia miocárdica o evento coronario agudo. La información de la mortalidad en el hospital y en el seguimiento a 30 días después de la admisión se obtuvo de los registros clínicos y del registro civil.

\section{Análisis estadístico}

Los resultados fueron expresados como valores promedio \pm desviación estándar para las variables medidas en escala numérica y en porcentaje para las medidas en escala nominal. Las variables cualitativas fueron comparadas mediante la prueba de chi cuadrado o test exacto de Fisher y las variables continuas con la prueba $t$ de Student. Las variables clínicas y de laboratorio medidas en la admisión al hospital asociadas a eventos adversos serios (admisión a UCI, uso de ventilación mecánica: VM, shock séptico, riesgo de complicaciones cardiovasculares o generales), estadía prolongada en el hospital ( $>7$ días) y muerte en el seguimiento a 30 días, fueron sometidas a análisis univariado y multivariado en un modelo de regresión logística (modalidad stepwise) que permite el control simultáneo de múltiples factores. De este modo, los parámetros que no agregaron valor predictivo no fueron retenidos en el modelo. Se calcularon las razones de probabilidad (odds ratio) e intervalos de confianza (IC) para 95\%. Las diferencias entre las variables fueron consideradas significativas con un valor de $p<0,05$. Para ello se utilizaron los programas MedCalc versión 17 (B-8400 Ostend, Belgium) y SPSS 24.0 (IBM SPSS Software, Chicago).

\section{Resultados}

Se enrolaron 659 adultos inmunocompetentes hospitalizados por neumonía adquirida en la comunidad, edad: $67 \pm 18$ años (rango: 18-101), $52 \%$ sexo masculino, $77 \%$ tenía enfermedades preexistentes, especialmente cardiovasculares, metabólicas, respiratorias y neurológicas crónicas. El $60 \%$ de los casos correspondían a las categorías de alto riesgo de Fine (clases IV y V) y la mitad cumplían los criterios de neumonía comunitaria grave (SCAP $\geq 10$ puntos), $40 \%$ fueron manejados en unidades de cuidado intermedio o UCI, $12 \%$ requirieron ventilación mecánica, $11 \%$ presentaron shock séptico y un tercio presentaron complicaciones en el hospital, especialmente cardiovasculares (15\%). La estadía media en el hospital fue de 9 días (rango: 1-108), cerca de la mitad estuvieron hospitalizados más de siete días, $7,1 \%$ fallecieron en el hospital y $9,9 \%$ en el seguimiento a 30 días (Tabla 1). La mayoría de los pacientes fueron manejados con cefalosporinas de tercera generación (92\%) en monoterapia 
Tabla 1. Características clínicas de los pacientes adultos inmunocompetentes hospitalizados por neumonía adquirida en la comunidad

\begin{tabular}{|c|c|}
\hline Variables & $\begin{array}{c}\text { Promedio } \pm \text { DE (Rango) } \\
\text { n (\%) }\end{array}$ \\
\hline $\mathrm{n}$ & 659 adultos \\
\hline Edad (años) & $67,5 \pm 18,8(18-101)$ \\
\hline Sexo (M-F) & $342-317(52-48 \%)$ \\
\hline PSI Score $>90$ puntos & $393(59,6 \%)$ \\
\hline CURB- $65 \geq 3$ puntos & $231(35,1 \%)$ \\
\hline SMART-COP $\geq 6$ puntos & $52(7,9 \%)$ \\
\hline $\mathrm{SCAP} \geq 10$ puntos & $341(51,7 \%)$ \\
\hline Comorbilidad & $506(76,8 \%)$ \\
\hline Enfermedad cardiovascular & $214(32,5 \%)$ \\
\hline Diabetes mellitus & $118(17,9 \%)$ \\
\hline Enfermedad neurológica crónica & $102(15,5 \%)$ \\
\hline Enfermedad pulmonar obstructiva crónica & $84(12,7 \%)$ \\
\hline Neumonía multilobar & $172(26,1 \%)$ \\
\hline Derrame pleural & $138(20,9 \%)$ \\
\hline Admisión a UCI & $153(23,2 \%)$ \\
\hline Uso de ventilación mecánica & $77(11,7 \%)$ \\
\hline Shock séptico & $71(10,8 \%)$ \\
\hline Complicaciones cardiovasculares & $98(14,9 \%)$ \\
\hline Complicaciones en el hospital & $206(31,3 \%)$ \\
\hline Estadía en el hospital (días) & $9,3 \pm 8,6(1-108)$ \\
\hline Mortalidad en el hospital & $47 \quad(7,1 \%)$ \\
\hline Mortalidad a 30 días & $65(9,9 \%)$ \\
\hline
\end{tabular}

Nota: M: masculino; F: femenino. UCI: Unidad de Cuidados Intensivos. Categorías de alto riesgo de los índices de gravedad de la neumonía: Pneumonia severity index (PSI Score), CURB-65, SMART-COP y SCAP. Los resultados se expresan como valores promedio \pm desviación estándar (DE) o número de casos y porcentaje.

o asociado a macrólidos (25\%) o quinolonas (15\%), siguiendo las recomendaciones de las guías clínicas ${ }^{12-15}$.

En la Tabla 2 se describen las variables clínicas y de laboratorio medidas en la admisión al hospital asociadas al riesgo de eventos adversos serios en el adulto inmunocompetente hospitalizado por neumonía adquirida en la comunidad (análisis univariado). La admisión a UCI fue más frecuente en los pacientes con enfermedades cardiovasculares, respiratorias o metabólicas crónicas, disnea, compromiso de conciencia, hipotensión arterial, taquipnea o disfunción renal en la admisión al hospital. El uso de ventilación mecánica fue más frecuente en los pacientes con alteración de los signos vitales (taquicardia, hipotensión arterial, ausencia de fiebre), disfunción renal, hiperkalemia y compromiso radiográfico multilobar; mientras que el shock séptico se presentó en pacientes con compromiso de conciencia, taquicardia, inestabilidad hemodinámica, disfunción renal o hiperglicemia en la admisión al hospital (Tabla 3).

La presencia de una o más complicaciones durante la hospitalización y la estadía prolongada en el hospital fueron más prevalentes en los pacientes con comorbilidades, dificultad respiratoria, inestabilidad hemodinámica, disfunción renal y derrame pleural. Los adultos mayores con enfermedad cardiovascular o enfermedad pulmonar obstructiva crónica, sospecha de aspiración, taquipnea y disfunción renal en la admisión al hospital presentaron mayores complicaciones cardiovasculares (Tabla 3). 
Tabla 2. Variables clínicas y de laboratorio medidas en la admisión al hospital predictoras de eventos adversos serios en el adulto inmunocompetente hospitalizado por neumonía adquirida en la comunidad. Análisis univariado

Admisión a UCI

\begin{tabular}{|c|c|c|c|c|c|}
\hline Predictores de admisión a UCI & UCI (+)/Total & UCI (-)/Total & OR & IC $95 \%$ & $\mathbf{p}$ \\
\hline Edad $\geq 65$ años & $113 / 153$ & $300 / 506$ & 1,94 & $1,30-2,90$ & 0,0012 \\
\hline Comorbilidades & $139 / 153$ & $367 / 506$ & 3,76 & $2,10-6,74$ & 0,0001 \\
\hline Cardiovascular & $76 / 153$ & $138 / 506$ & 2,63 & $1,81-3,82$ & 0,0001 \\
\hline Diabetes & $37 / 153$ & $81 / 506$ & 1,67 & $1,08-2,60$ & 0,0217 \\
\hline EPOC & $33 / 153$ & $51 / 506$ & 2,45 & $1,52-3,97$ & 0,0003 \\
\hline Insuficiencia renal crónica & $20 / 153$ & $26 / 506$ & 2,78 & $1,50-5,13$ & 0,0011 \\
\hline Fiebre & $89 / 153$ & $369 / 506$ & 0,52 & $0,35-0,75$ & 0,0006 \\
\hline Disnea & $131 / 153$ & $316 / 506$ & 3,58 & $2,20-5,82$ & 0,0001 \\
\hline Compromiso conciencia & $50 / 153$ & $82 / 506$ & 2,51 & $1,66-3,79$ & 0,0001 \\
\hline Escalofríos & $35 / 153$ & $175 / 506$ & 0,56 & $0,37-0,85$ & 0,0069 \\
\hline $\mathrm{FC} \geq 120 \mathrm{ciclos} / \mathrm{min}$ & $38 / 152$ & $80 / 503$ & 1,76 & $1,14-2,73$ & 0,0112 \\
\hline PA Sistólica $<90 \mathrm{mmHg}$ & $21 / 151$ & $24 / 502$ & 3,19 & $1,72-5,92$ & 0,0002 \\
\hline PA Diastólica $<60 \mathrm{mmHg}$ & $54 / 151$ & $92 / 502$ & 2,48 & $1,66-3,71$ & 0,0001 \\
\hline $\mathrm{FR} \geq 30 \mathrm{ciclos} / \mathrm{min}$ & $93 / 148$ & $206 / 454$ & 2,04 & $1,39-2,98$ & 0,0003 \\
\hline Temperatura $\leq 36{ }^{\circ} \mathrm{C}$ & $22 / 150$ & $29 / 494$ & 2,76 & $1,53-4,96$ & 0,0007 \\
\hline $\mathrm{BUN}>20 \mathrm{mg} / \mathrm{dL}$ & $95 / 149$ & $192 / 480$ & 2,64 & $1,80-3,86$ & 0,0001 \\
\hline Creatininemia $>1,2 \mathrm{mg} / \mathrm{dL}$ & $76 / 149$ & $146 / 474$ & 2,34 & $1,61-3,41$ & 0,0001 \\
\hline Potasio $>5 \mathrm{mEq} / \mathrm{L}$ & $16 / 137$ & $19 / 460$ & 3,07 & $1,53-6,15$ & 0,0016 \\
\hline $\mathrm{pH}$ arterial $<7,35$ & $28 / 137$ & $9 / 371$ & 10,3 & $4,73-22,5$ & 0,0001 \\
\hline $\mathrm{PaCO}_{2}>45 \mathrm{mmHg}$ & $26 / 137$ & $16 / 371$ & 5,20 & $2,69-10,0$ & 0,0001 \\
\hline Bicarbonato $<18 \mathrm{mEq} / \mathrm{L}$ & $29 / 133$ & $36 / 370$ & 2,59 & $1,51-4,42$ & 0,0005 \\
\hline $\mathrm{PaO}_{2} / \mathrm{FiO}_{2} \leq 250 \mathrm{mmHg}$ & $98 / 127$ & $125 / 334$ & 5,65 & $3,53-9,04$ & 0,0001 \\
\hline Glicemia $>130 \mathrm{mg} / \mathrm{dL}$ & $81 / 144$ & $190 / 467$ & 1,87 & $1,29-2,73$ & 0,0011 \\
\hline NAC multilobar & $58 / 148$ & $114 / 497$ & 2,17 & $1,47-3,20$ & 0,0001 \\
\hline Etiología conocida & $67 / 153$ & $147 / 506$ & 1,90 & $1,31-2,76$ & 0,0007 \\
\hline Hemocultivos $(+)$ & $21 / 138$ & $40 / 448$ & 1,83 & $1,04-3,23$ & 0,0365 \\
\hline
\end{tabular}

Nota: UCI: Unidad de Cuidados Intensivos, OR: Odds ratio, IC95\%: Intervalo de confianza de 95\%, EPOC: Enfermedad Pulmonar Obstructiva Crónica, FC: Frecuencia cardiaca, PA: Presión arterial, FR: Frecuencia respiratoria, BUN: Nitrógeno ureico sérico, NAC: Neumonía adquirida en la comunidad.

Uso de Ventilación Mecánica

\begin{tabular}{|lccccc|}
\hline Predictores uso de VM & VM (+)/Total & VM (-)/Total & OR & IC 95\% & p \\
Comorbilidades & $71 / 77$ & $435 / 582$ & 4,00 & $1,70-9,39$ & 0,0015 \\
Fiebre & $43 / 77$ & $415 / 582$ & 0,51 & $0,31-0,83$ & 0,0063 \\
Tos & $57 / 77$ & $487 / 582$ & 0,56 & $0,32-0,96$ & 0,0381 \\
Disnea & $67 / 77$ & $380 / 582$ & 3,56 & $1,79-7,07$ & 0,0003 \\
Compromiso conciencia & $32 / 77$ & $100 / 582$ & 3,43 & $2,08-5,66$ & 0,0001 \\
Escalofríos & $14 / 77$ & $196 / 582$ & 0,44 & $0,24-0,80$ & 0,0073 \\
FC $\geq 120$ ciclos/min & $24 / 76$ & $94 / 579$ & 2,38 & $1,40-4,05$ & 0,0014 \\
PA Sistólica $<90 \mathrm{mmHg}$ & $16 / 76$ & $29 / 577$ & 5,04 & $2,59-9,81$ & 0,0001 \\
PA Diastólica $<60 \mathrm{mmHg}$ & $27 / 76$ & $119 / 577$ & 2,12 & $1,27-3,54$ & 0,0039 \\
\hline
\end{tabular}




\begin{tabular}{|c|c|c|c|c|c|}
\hline Predictores uso de VM & VM (+)/Total & VM (-)/Total & OR & IC $95 \%$ & $\mathbf{p}$ \\
\hline $\mathrm{FR} \geq 30$ ciclos $/ \mathrm{min}$ & $48 / 74$ & $251 / 528$ & 2,04 & $1,23-3,38$ & 0,0059 \\
\hline Temperatura $\leq 36^{\circ} \mathrm{C}$ & $18 / 76$ & $33 / 568$ & 5,03 & $2,67-9,49$ & 0,0001 \\
\hline Leucocitos $<4.000 / \mathrm{mm}^{3}$ & $7 / 74$ & $11 / 578$ & 5,39 & $2,02-14,36$ & 0,0008 \\
\hline $\mathrm{BUN}>20 \mathrm{mg} / \mathrm{dL}$ & $47 / 75$ & $240 / 554$ & 2,20 & $1,34-3,61$ & 0,0019 \\
\hline Creatininemia $>1,2 \mathrm{mg} / \mathrm{dL}$ & $36 / 75$ & $186 / 548$ & 1,80 & $1,11-2,92$ & 0,0182 \\
\hline Potasio $>5 \mathrm{mEq} / \mathrm{L}$ & $11 / 71$ & $24 / 526$ & 3,84 & $1,79-8,22$ & 0,0005 \\
\hline $\mathrm{pH}$ arterial $<7,35$ & $25 / 73$ & $12 / 435$ & 18,36 & $8,67-38,88$ & 0,0001 \\
\hline $\mathrm{PaCO}_{2}>45 \mathrm{mmHg}$ & $19 / 74$ & $23 / 434$ & 6,17 & $3,16-12,06$ & 0,0001 \\
\hline Bicarbonato $<18 \mathrm{mEq} / \mathrm{L}$ & $19 / 72$ & $46 / 431$ & 3,00 & $1,64-5,50$ & 0,0004 \\
\hline $\mathrm{PaO}_{2} / \mathrm{FiO}_{2} \leq 250 \mathrm{mmHg}$ & $54 / 71$ & $169 / 390$ & 4,15 & $2,32-7,42$ & 0,0001 \\
\hline PCR sérica $\geq 30 \mathrm{mg} / \mathrm{dL}$ & $24 / 60$ & $110 / 494$ & 2,33 & $1,33-4,07$ & 0,0030 \\
\hline Albúmina $\leq 3 \mathrm{~g} / \mathrm{dL}$ & $29 / 74$ & $135 / 538$ & 1,92 & $1,16-3,19$ & 0,0112 \\
\hline Glicemia $>200 \mathrm{mg} / \mathrm{dL}$ & $16 / 75$ & $66 / 536$ & 1,93 & $1,05-3,55$ & 0,0343 \\
\hline NAC multilobar & $40 / 75$ & $132 / 570$ & 3,79 & $2,32-6,21$ & 0,0001 \\
\hline Etiología conocida & $37 / 77$ & $177 / 582$ & 2,12 & $1,31-3,42$ & 0,0022 \\
\hline Hemocultivos $(+)$ & $14 / 73$ & $47 / 513$ & 2,35 & $1,22-4,53$ & 0,0105 \\
\hline
\end{tabular}

Nota: VM: Ventilación mecánica, OR: Odds ratio, IC95\%: Intervalo de confianza de 95\%, FC: Frecuencia cardiaca, PA: Presión arterial, FR: Frecuencia respiratoria, BUN: Nitrógeno ureico sérico, PCR: Proteína C reactiva, NAC: Neumonía adquirida en la comunidad.

\section{Shock séptico}

\begin{tabular}{|lccccc|}
\hline Predictor de shock séptico & Shock $(+) /$ Total & Shock (-)/Total & OR & IC 95\% & p \\
\hline Insuficiencia renal crónica & $9 / 71$ & $37 / 588$ & 2,16 & $1,00-4,69$ & 0,0510 \\
\hline Sospecha de aspiración & $13 / 71$ & $46 / 588$ & 2,64 & $1,35-5,17$ & 0,0047 \\
\hline Fiebre & $38 / 71$ & $420 / 588$ & 0,46 & $0,28-0,76$ & 0,0024 \\
\hline Tos & $52 / 71$ & $492 / 588$ & 0,53 & $0,30-0,94$ & 0,0307 \\
\hline Disnea & $57 / 71$ & $390 / 588$ & 2,07 & $1,12-3,80$ & 0,0195 \\
\hline Compromiso de conciencia & $32 / 71$ & $100 / 588$ & 4,00 & $2,39-2,70$ & 0,0001 \\
\hline Escalofríos & $14 / 71$ & $196 / 588$ & 0,49 & $0,27-0,90$ & 0,0222 \\
\hline FC $\geq 120$ ciclos $/ \mathrm{min}$ & $19 / 70$ & $99 / 585$ & 1,83 & $1,03-3,23$ & 0,0377 \\
\hline PA Sistólica $<90 \mathrm{mmHg}$ & $22 / 70$ & $23 / 583$ & 11,16 & $5,80-21,48$ & 0,0001 \\
\hline PA Diastólica $<60 \mathrm{mmHg}$ & $34 / 70$ & $160 / 583$ & 2,50 & $1,51-4,13$ & 0,0004 \\
\hline FR $\geq 30$ ciclos $/ \mathrm{min}$ & $44 / 68$ & $255 / 534$ & 2,01 & $1,19-3,39$ & 0,0094 \\
\hline Temperatura $\leq 36{ }^{\circ} \mathrm{C}$ & $14 / 70$ & $37 / 574$ & 3,63 & $1,85-7,12$ & 0,0002 \\
\hline Leucocitos $<4.000 / \mathrm{mm}^{3}$ & $5 / 69$ & $13 / 583$ & 3,43 & $1,18-9,92$ & 0,0232 \\
\hline Leucocitos $\geq 30.000 / \mathrm{mm}^{3}$ & $5 / 69$ & $14 / 583$ & 3,18 & $1,11-9,10$ & 0,0316 \\
\hline Neutrófilos $<4.000 / \mathrm{mm}^{3}$ & $10 / 66$ & $30 / 566$ & 3,19 & $1,48-6,87$ & 0,0030 \\
\hline VHS $\geq 50 \mathrm{~mm} / \mathrm{h}$ & $30 / 62$ & $356 / 552$ & 0,52 & $0,30-0,87$ & 0,0140 \\
\hline $\mathrm{BUN}>24 \mathrm{mg} / \mathrm{dL}$ & $39 / 69$ & $176 / 560$ & 2,84 & $1,71-4,72$ & 0,0001 \\
\hline $\mathrm{Creatininemia}>1,2 \mathrm{mg} / \mathrm{dL}$ & $37 / 67$ & $185 / 556$ & 2,47 & $1,48-4,13$ & 0,0005 \\
\hline Potasio $>5 \mathrm{mEq} / \mathrm{L}$ & $10 / 66$ & $25 / 531$ & 3,61 & $1,65-7,91$ & 0,0013 \\
\hline pH arterial $<7,35$ & $23 / 63$ & $14 / 445$ & 17,70 & $8,45-37,07$ & 0,0001 \\
\hline PaCO ${ }_{2}>45 \mathrm{mmHg}$ & $16 / 63$ & $26 / 445$ & 5,49 & $2,75-10,96$ & 0,0001 \\
\hline Bicarbonato $<18 \mathrm{mEq} / \mathrm{L}$ & $19 / 60$ & $46 / 443$ & 4,00 & $2,14-7,46$ & 0,0001 \\
\hline
\end{tabular}




\begin{tabular}{|lccccc|}
\hline Predictor de shock séptico & Shock (+)/Total & Shock (-)/Total & OR & IC 95\% & p \\
$\mathrm{PaO}_{2} / \mathrm{FiO}_{2} \leq 250 \mathrm{mmHg}$ & $46 / 61$ & $177 / 400$ & 3,86 & $2,09-7,15$ & 0,0001 \\
\hline $\mathrm{PCR}$ sérica $\geq 30 \mathrm{mg} / \mathrm{dL}$ & $20 / 55$ & $114 / 499$ & 1,93 & $1,07-3,47$ & 0,0284 \\
Glicemia $>130 \mathrm{mg} / \mathrm{dL}$ & $42 / 69$ & $229 / 542$ & 2,13 & $1,27-3,55$ & 0,0039 \\
$\mathrm{NAC}$ multilobar & $32 / 70$ & $140 / 575$ & 2,62 & $1,58-4,35$ & 0,0002 \\
\hline Etiología conocida & $36 / 71$ & $178 / 588$ & 2,37 & $1,44-3,90$ & 0,0007 \\
Hemocultivos (+) & $12 / 69$ & $49 / 517$ & 2,01 & $1,01-4,00$ & 0,0468 \\
Uso de ventilación mecánica & $47 / 71$ & $30 / 588$ & 36,43 & $19,72-67,29$ & 0,0001 \\
Complicación en el hospital & $64 / 71$ & $142 / 588$ & 28,72 & $12,87-64,09$ & 0,0001 \\
\hline Estadía hospital > 7 días & $58 / 71$ & $238 / 588$ & 6,56 & $3,52-12,24$ & 0,0001 \\
\hline
\end{tabular}

Nota: OR: Odds ratio, IC95\%: Intervalo de confianza de 95\%, FC: Frecuencia cardiaca, PA: Presión arterial, FR: Frecuencia respiratoria, VHS: Velocidad de eritrosedimentación, BUN: Nitrógeno ureico sérico, PCR: Proteína C reactiva, NAC: Neumonía adquirida en la comunidad.

\section{Complicaciones cardiovasculares}

\begin{tabular}{|c|c|c|c|c|c|}
\hline Complicaciones cardiovasculares & Cardio $(+) /$ Total & Cardio (-)/Total & OR & IC $95 \%$ & $\mathbf{p}$ \\
\hline Edad $\geq 65$ años & $87 / 98$ & $326 / 561$ & 5,70 & $2,98-10,91$ & 0,0001 \\
\hline Admisión a UTIM-UCI & $66 / 98$ & $196 / 561$ & 3,84 & $2,43-6,06$ & 0,0001 \\
\hline Comorbilidades & $95 / 98$ & $411 / 561$ & 11,56 & $3,61-37,03$ & 0,0001 \\
\hline Cardiovascular & $60 / 98$ & $154 / 561$ & 4,17 & $2,67-6,52$ & 0,0001 \\
\hline EPOC & $24 / 98$ & $60 / 561$ & 2,71 & $1,59-4,61$ & 0,0002 \\
\hline Insuficiencia renal crónica & $12 / 98$ & $34 / 561$ & 2,16 & $1,08-4,34$ & 0,0299 \\
\hline Sospecha aspiración & $17 / 98$ & $42 / 561$ & 2,59 & $1,41-4,77$ & 0,0022 \\
\hline Fiebre & $53 / 98$ & $405 / 561$ & 0,45 & $0,29-0,70$ & 0,0004 \\
\hline Tos & $73 / 98$ & $471 / 561$ & 0,56 & $0,34-0,93$ & 0,0241 \\
\hline Dolor torácico & $11 / 98$ & $124 / 561$ & 0,45 & $0,23-0,86$ & 0,0161 \\
\hline Disnea & $80 / 98$ & $367 / 561$ & 2,35 & $1,37-4,03$ & 0,0019 \\
\hline Escalofríos & $22 / 98$ & $188 / 561$ & 0,57 & $0,35-0,95$ & 0,0317 \\
\hline $\mathrm{FR} \geq 30$ ciclos $/ \mathrm{min}$ & $61 / 94$ & $238 / 508$ & 2,10 & $1,33-3,32$ & 0,0015 \\
\hline Temperatura $\leq 36{ }^{\circ} \mathrm{C}$ & $14 / 95$ & $37 / 549$ & 2,39 & $1,24-4,62$ & 0,0094 \\
\hline $\mathrm{BUN}>20 \mathrm{mg} / \mathrm{dL}$ & $67 / 97$ & $220 / 532$ & 3,17 & $1,99-5,04$ & 0,0001 \\
\hline Creatininemia $>1,2 \mathrm{mg} / \mathrm{dL}$ & $49 / 98$ & $173 / 525$ & 2,03 & $1,32-3,15$ & 0,0014 \\
\hline Sodio $>145 \mathrm{mEq} / \mathrm{L}$ & $6 / 97$ & $10 / 518$ & 3,35 & $1,19-9,44$ & 0,0223 \\
\hline Potasio $>5 \mathrm{mEq} / \mathrm{L}$ & $10 / 92$ & $25 / 505$ & 2,34 & $1,08-5,06$ & 0,0303 \\
\hline $\mathrm{pH}$ arterial $<7,35$ & $13 / 90$ & $24 / 418$ & 2,77 & $1,35-5,68$ & 0,0054 \\
\hline $\mathrm{PaCO}_{2}>45 \mathrm{mmHg}$ & $15 / 90$ & $27 / 418$ & 2,90 & $1,47-5,70$ & 0,0021 \\
\hline $\mathrm{PaO}_{2} / \mathrm{FiO}_{2}<285 \mathrm{mmHg}$ & $66 / 85$ & $240 / 376$ & 1,97 & $1,13-3,42$ & 0,0162 \\
\hline Albúmina $\leq 3 \mathrm{~g} / \mathrm{dL}$ & $74 / 96$ & $137 / 514$ & 9,26 & $5,53-15,48$ & 0,0001 \\
\hline Glicemia $>130 \mathrm{mg} / \mathrm{dL}$ & $55 / 95$ & $216 / 516$ & 1,91 & $1,23-2,97$ & 0,0042 \\
\hline NAC multilobar & $33 / 95$ & $139 / 550$ & 0,53 & $0,33-0,86$ & 0,0106 \\
\hline Uso de VM & $23 / 98$ & $54 / 561$ & 2,88 & $1,67-4,97$ & 0,0001 \\
\hline Complicación en el hospital & $93 / 98$ & $113 / 561$ & 73,74 & $29,3-185,6$ & 0,0001 \\
\hline Estadía hospital > 7 días & $70 / 98$ & $226 / 561$ & 3,71 & $2,32-5,93$ & 0,0001 \\
\hline
\end{tabular}

Nota: Cardio: Complicaciones cardiovasculares, OR: Odds ratio, IC95\%: Intervalo de confianza de 95\%, UTIM: Unidad de Cuidado Intermedio, UCI: Unidad de Cuidados Intensivos, EPOC: Enfermedad Pulmonar Obstructiva Crónica, FR: Frecuencia respiratoria, BUN: Nitrógeno ureico sérico, NAC: Neumonía adquirida en la comunidad, VM: Ventilación mecánica. 


\section{Complicaciones en el hospital}

\begin{tabular}{|c|c|c|c|c|c|}
\hline Predictor de complicación & Compl (+)/Total & Compl (-)/Total & OR & IC 95\% & $\mathbf{p}$ \\
\hline Edad $\geq 65$ años & $141 / 206$ & $272 / 453$ & 1,44 & $1,02-2,05$ & 0,0392 \\
\hline Admisión a UTIM-UCI & $127 / 206$ & $135 / 453$ & 3,79 & $2,68-5,35$ & 0,0001 \\
\hline Uso previo de antibióticos & $58 / 198$ & $119 / 437$ & 0,41 & $0,28-0,62$ & 0,0001 \\
\hline Comorbilidades & $186 / 206$ & $320 / 453$ & 3,87 & $2,34-6,40$ & 0,0001 \\
\hline Cardiovascular & $97 / 206$ & $116 / 453$ & 2,59 & $1,83-3,65$ & 0,0001 \\
\hline Diabetes & $49 / 206$ & $68 / 453$ & 1,77 & $1,17-2,67$ & 0,0067 \\
\hline EPOC & $35 / 206$ & $49 / 453$ & 1,69 & $1,06-2,70$ & 0,0288 \\
\hline Enfermedad hepática crónica & $11 / 206$ & $10 / 453$ & 2,50 & $1,04-5,98$ & 0,0397 \\
\hline Sospecha de aspiración & $28 / 206$ & $34 / 453$ & 1,94 & $1,14-3,29$ & 0,0144 \\
\hline Fiebre & $126 / 206$ & $333 / 453$ & 0,57 & $0,40-0,80$ & 0,0015 \\
\hline Tos & $158 / 206$ & $385 / 453$ & 0,58 & $0,38-0,88$ & 0,0101 \\
\hline Disnea & $161 / 206$ & $284 / 453$ & 2,13 & $1,45-3,12$ & 0,0001 \\
\hline Compromiso conciencia & $60 / 206$ & $73 / 453$ & 2,14 & $1,45-3,16$ & 0,0001 \\
\hline Escalofríos & $52 / 206$ & $157 / 450$ & 0,63 & $0,44-0,91$ & 0,0143 \\
\hline PA Sistólica $<90 \mathrm{mmHg}$ & $28 / 202$ & $20 / 451$ & 3,47 & $1,90-6,32$ & 0,0001 \\
\hline PA Diastólica $<60 \mathrm{mmHg}$ & $60 / 202$ & $89 / 451$ & 1,72 & $1,17-2,51$ & 0,0053 \\
\hline $\mathrm{FR} \geq 30 \mathrm{ciclos} / \mathrm{min}$ & $118 / 193$ & $182 / 408$ & 1,95 & $2,38-2,77$ & 0,0002 \\
\hline Temperatura $\leq 36{ }^{\circ} \mathrm{C}$ & $26 / 201$ & $25 / 444$ & 2,49 & $1,40-4,43$ & 0,0019 \\
\hline $\mathrm{VHS} \geq 120 \mathrm{~mm} / \mathrm{h}$ & $19 / 189$ & $19 / 425$ & 2,39 & $1,23-4,62$ & 0,0098 \\
\hline $\mathrm{BUN}>20 \mathrm{mg} / \mathrm{dL}$ & $129 / 199$ & $158 / 430$ & 3,17 & $2,23-4,51$ & 0,0001 \\
\hline Creatininemia $>1,2 \mathrm{mg} / \mathrm{dL}$ & $102 / 201$ & $121 / 420$ & 2,55 & $1,80-3,61$ & 0,0001 \\
\hline Potasio $>5 \mathrm{mEq} / \mathrm{L}$ & $17 / 192$ & $19 / 405$ & 1,97 & $1,00-3,89$ & 0,0495 \\
\hline $\mathrm{pH}$ arterial $<7,35$ & $26 / 180$ & $11 / 328$ & 4,87 & $2,34-10,10$ & 0,0001 \\
\hline $\mathrm{PaCO}_{2}>45 \mathrm{mmHg}$ & $23 / 181$ & $19 / 327$ & 2,36 & $1,25-4,46$ & 0,0083 \\
\hline Bicarbonato $<18 \mathrm{mEq} / \mathrm{L}$ & $33 / 178$ & $31 / 325$ & 2,16 & $1,27-3,66$ & 0,0044 \\
\hline $\mathrm{PaO}_{2} / \mathrm{FiO}_{2} \leq 250 \mathrm{mmHg}$ & $93 / 169$ & $132 / 294$ & 1,50 & $1,03-2,20$ & 0,0361 \\
\hline PCR sérica $\geq 30 \mathrm{mg} / \mathrm{dL}$ & $57 / 175$ & $77 / 379$ & 1,89 & $1,27-2,84$ & 0,0019 \\
\hline Albúmina $\leq 3 \mathrm{~g} / \mathrm{dL}$ & $65 / 196$ & $99 / 415$ & 1,58 & $1,09-2,30$ & 0,0158 \\
\hline Glicemia $>130 \mathrm{mg} / \mathrm{dL}$ & $105 / 195$ & $165 / 414$ & 1,76 & $1,25-2,48$ & 0,0012 \\
\hline NAC multilobar & $71 / 202$ & $101 / 443$ & 1,84 & $1,27-2,64$ & 0,0011 \\
\hline Derrame pleural & $68 / 202$ & $70 / 445$ & 2,72 & $1,84-4,01$ & 0,0001 \\
\hline Etiología conocida & $81 / 206$ & $132 / 453$ & 1,58 & $1,12-2,23$ & 0,0098 \\
\hline Hemocultivos $(+)$ & $28 / 189$ & $36 / 397$ & 1,74 & $1,03-3,00$ & 0,0388 \\
\hline Uso de VM & $57 / 206$ & $20 / 453$ & 8,28 & $4,82-14,25$ & 0,0001 \\
\hline
\end{tabular}

Nota: Compl: Complicaciones en el hospital, OR: Odds ratio, IC95\%: Intervalo de confianza de 95\%, UTIM-UCI: Unidad de Cuidado Intermedio-Unidad de Cuidado Intensivo, EPOC: Enfermedad Pulmonar Obstructiva Crónica, PA: Presión arterial, FR: Frecuencia respiratoria, VHS: Velocidad de eritrosedimentación, BUN: Nitrógeno ureico sérico, PCR: Proteína C reactiva, NAC: Neumonía adquirida en la comunidad, VM: Ventilación mecánica.

\section{Estadía prolongada en el hospital ( $>7$ días)}

\begin{tabular}{|lccccc|}
\hline Predictor de estadía prolongada & Estadía (+)/Total & Estadía (-)/Total & OR & IC 95\% & p \\
\hline Edad $\geq 80$ años & $108 / 296$ & $95 / 363$ & 1,62 & $1,16-2,26$ & 0,0045 \\
\hline Admisión a UTIM-UCI & $174 / 296$ & $88 / 363$ & 4,46 & $3,19-6,22$ & 0,0001 \\
Comorbilidades & $257 / 296$ & $249 / 363$ & 3,02 & $2,02-4,52$ & 0,0001 \\
\hline Enfermedad neurológica & $64 / 296$ & $38 / 363$ & 2,36 & $1,53-3,65$ & 0,0001 \\
\hline Sospecha de aspiración & $42 / 296$ & $20 / 363$ & 2,84 & $1,63-4,95$ & 0,0002 \\
\hline
\end{tabular}




\begin{tabular}{|c|c|c|c|c|c|}
\hline Predictor de estadía prolongada & Estadía $(+) /$ Total & Estadía (-)/Total & OR & IC $95 \%$ & $\mathbf{p}$ \\
\hline Fiebre & $192 / 296$ & $267 / 363$ & 0,66 & $0,48-0,93$ & 0,0161 \\
\hline Disnea & $222 / 296$ & $223 / 363$ & 1,88 & $1,34-2,64$ & 0,0002 \\
\hline Compromiso conciencia & $96 / 296$ & $37 / 363$ & 4,23 & $2,78-6,42$ & 0,0001 \\
\hline Escalofríos & $78 / 296$ & $131 / 360$ & 0,63 & $0,45-0,88$ & 0,0062 \\
\hline PA Sistólica $<90 \mathrm{mmHg}$ & $29 / 292$ & $19 / 361$ & 1,98 & $1,09-3,62$ & 0,0252 \\
\hline PA Diastólica $<60 \mathrm{mmHg}$ & $80 / 292$ & $69 / 361$ & 1,60 & $1,11-2,31$ & 0,0125 \\
\hline $\mathrm{FR}>20 \mathrm{ciclos} / \mathrm{min}$ & $249 / 273$ & $317 / 328$ & 0,36 & $0,17-0,75$ & 0,0063 \\
\hline Temperatura $\leq 37^{\circ} \mathrm{C}$ & $119 / 291$ & $108 / 354$ & 1,58 & $1,14-2,18$ & 0,0061 \\
\hline $\mathrm{VHS} \geq 120 \mathrm{~mm} / \mathrm{h}$ & $23 / 269$ & $15 / 345$ & 2,06 & $1,05-4,02$ & 0,0352 \\
\hline $\mathrm{BUN}>20 \mathrm{mg} / \mathrm{dL}$ & $166 / 288$ & $121 / 341$ & 2,47 & $1,79-3,41$ & 0,0001 \\
\hline Creatininemia $>1,2 \mathrm{mg} / \mathrm{dL}$ & $122 / 287$ & $101 / 334$ & 1,71 & $1,23-2,37$ & 0,0015 \\
\hline $\mathrm{pH}$ arterial $<7,35$ & $30 / 250$ & $7 / 258$ & 4,89 & $2,11-11,35$ & 0,0002 \\
\hline $\mathrm{PaCO}_{2}>45 \mathrm{mmHg}$ & $34 / 250$ & $8 / 258$ & 4,92 & $2,24-10,85$ & 0,0001 \\
\hline $\mathrm{PaO}_{2} / \mathrm{FiO}_{2} \leq 250 \mathrm{mmHg}$ & $144 / 233$ & $81 / 230$ & 2,98 & $2,04-4,34$ & 0,0001 \\
\hline Albúmina $<3,5 \mathrm{~g} / \mathrm{dL}$ & $187 / 279$ & $165 / 332$ & 2,06 & $1,48-2,86$ & 0,0001 \\
\hline Glicemia $>130 \mathrm{mg} / \mathrm{dL}$ & $143 / 278$ & $127 / 331$ & 1,70 & $1,23-2,35$ & 0,0013 \\
\hline NAC multilobar & $97 / 293$ & $75 / 352$ & 1,83 & $1,28-2,60$ & 0,0008 \\
\hline Derrame pleural & $88 / 293$ & $50 / 353$ & 2,60 & $1,76-3,84$ & 0,0001 \\
\hline Etiología conocida & $111 / 296$ & $102 / 363$ & 1,54 & $1,11-2,13$ & 0,0105 \\
\hline Uso de VM & $62 / 296$ & $15 / 363$ & 6,15 & $3,41-11,06$ & 0,0001 \\
\hline Complicación en hospital & $143 / 296$ & $63 / 363$ & 4,45 & $3,12-6,35$ & 0,0001 \\
\hline
\end{tabular}

Nota: Estadía: Estadía mayor de 7 días en el hospital, OR: Odds ratio, IC95\%: Intervalo de confianza de 95\%, UTIMUCI: Unidad de Cuidado Intermedio-Unidad de Cuidado Intensivo, PA: Presión arterial, FR: Frecuencia respiratoria, VHS: Velocidad de eritrosedimentación, BUN: Nitrógeno ureico sérico, NAC: Neumonía adquirida en la comunidad, VM: Ventilación mecánica.

Mortalidad a 30 días
\begin{tabular}{|lccccc|}
\hline Predictor de muerte & Fallece (+)/Total & Fallece (-)/Total & OR & IC 95\% & p \\
\hline Edad $\geq 65$ años & $56 / 65$ & $355 / 591$ & 4,14 & $2,01-8,52$ & 0,0001 \\
\hline Admisión a UTIM-UCI & $45 / 65$ & $215 / 591$ & 3,94 & $2,26-6,84$ & 0,0001 \\
\hline Comorbilidades & $59 / 65$ & $445 / 591$ & 3,23 & $1,36-7,63$ & 0,0076 \\
Cardiovascular & $31 / 65$ & $181 / 591$ & 2,07 & $1,23-3,46$ & 0,0060 \\
\hline Enfermedad neurológica & $25 / 65$ & $77 / 591$ & 4,17 & $2,40-7,26$ & 0,0001 \\
\hline Sospecha aspiración & $15 / 65$ & $44 / 591$ & 3,73 & $1,94-7,17$ & 0,0001 \\
\hline Fiebre & $34 / 65$ & $411 / 591$ & 0,48 & $0,29-0,81$ & 0,0055 \\
\hline Tos & $47 / 65$ & $494 / 591$ & 0,51 & $0,29-0,92$ & 0,0253 \\
\hline Dolor torácico & $6 / 65$ & $129 / 591$ & 0,36 & $0,15-0,86$ & 0,0217 \\
\hline Disnea & $53 / 65$ & $392 / 591$ & 2,24 & $1,17-4,29$ & 0,0148 \\
\hline Compromiso conciencia & $33 / 65$ & $99 / 591$ & 5,13 & $3,01-8,72$ & 0,0001 \\
\hline Escalofríos & $5 / 65$ & $204 / 591$ & 0,16 & $0,06-0,40$ & 0,0001 \\
\hline PA Sistólica $<90 \mathrm{mmHg}$ & $13 / 63$ & $32 / 587$ & 4,51 & $2,22-9,14$ & 0,0001 \\
\hline PA Diastólica $\leq 50 \mathrm{mmHg}$ & $12 / 63$ & $52 / 587$ & 2,42 & $1,21-4,83$ & 0,0121 \\
\hline FR $\geq 30$ resp/min & $50 / 61$ & $257 / 538$ & 4,97 & $2,53-9,75$ & 0,0001 \\
\hline Temperatura $\leq 37^{\circ} \mathrm{C}$ & $36 / 62$ & $191 / 580$ & 2,82 & $1,65-4,81$ & 0,0001 \\
\hline
\end{tabular}




\begin{tabular}{|c|c|c|c|c|c|}
\hline Predictor de muerte & Fallece $(+) /$ Total & Fallece (-)/Total & OR & IC $95 \%$ & $\mathbf{p}$ \\
\hline Neutrófilos $<4.000 / \mathrm{mm}^{3}$ & $9 / 60$ & $31 / 567$ & 3,05 & $1,38-6,76$ & 0,0060 \\
\hline $\mathrm{BUN}>20 \mathrm{mg} / \mathrm{dL}$ & $43 / 62$ & $242 / 562$ & 2,99 & $1,70-5,27$ & 0,0001 \\
\hline Creatininemia $>1,2 \mathrm{mg} / \mathrm{dL}$ & $30 / 62$ & $190 / 556$ & 1,81 & $1,07-3,06$ & 0,0282 \\
\hline Sodio $<135 \mathrm{mEq} / \mathrm{L}$ & $33 / 61$ & $153 / 551$ & 3,07 & $1,79-5,25$ & 0,0001 \\
\hline Sodio $>145 \mathrm{mEq} / \mathrm{L}$ & $6 / 61$ & $10 / 551$ & 5,90 & $2,07-16,86$ & 0,0009 \\
\hline Potasio $>5 \mathrm{mEq} / \mathrm{L}$ & $7 / 59$ & $27 / 535$ & 2,53 & $1,05-6,10$ & 0,0382 \\
\hline $\mathrm{pH}$ arterial $<7,35$ & $10 / 58$ & $25 / 447$ & 3,52 & $1,59-7,76$ & 0,0019 \\
\hline $\mathrm{PaO}_{2} / \mathrm{FiO}_{2} \leq 250 \mathrm{mmHg}$ & $42 / 56$ & $179 / 402$ & 3,74 & $1,98-7,06$ & 0,0001 \\
\hline $\mathrm{PCR}$ sérica $<5 \mathrm{mg} / \mathrm{dL}$ & $14 / 51$ & $74 / 499$ & 2,17 & $1,12-4,22$ & 0,0217 \\
\hline Albúmina $\leq 3 \mathrm{~g} / \mathrm{dL}$ & $34 / 61$ & $129 / 545$ & 4,06 & $2,36-6,99$ & 0,0001 \\
\hline Glicemia $>130 \mathrm{mg} / \mathrm{dL}$ & $37 / 61$ & $232 / 545$ & 2,08 & $1,21-3,57$ & 0,0080 \\
\hline NAC multilobar & $26 / 65$ & $146 / 579$ & 1,98 & $1,16-3,36$ & 0,0118 \\
\hline Derrame pleural & $23 / 65$ & $115 / 579$ & 2,21 & $1,28-3,82$ & 0,0046 \\
\hline Etiología conocida & $29 / 65$ & $184 / 591$ & 1,78 & $1,06-2,99$ & 0,0292 \\
\hline Uso de VM & $28 / 65$ & $49 / 591$ & 8,37 & $4,73-14,82$ & 0,0001 \\
\hline Complicación en hospital & $47 / 65$ & $159 / 591$ & 7,09 & $4,00-12,58$ & 0,0001 \\
\hline Estadía en hospital $>14 \mathrm{~d}$ & $19 / 65$ & $75 / 591$ & 2,84 & $1,58-5,11$ & 0,0005 \\
\hline
\end{tabular}

Nota: OR: Odds ratio, IC95\%: Intervalo de confianza de 95\%, UTIM-UCI: Unidad de Cuidado Intermedio-Unidad de Cuidado Intensivo, PA: Presión arterial, FR: Frecuencia respiratoria, BUN: Nitrógeno ureico sérico, PCR: Proteína C reactiva, NAC: Neumonía adquirida en la comunidad, VM: Ventilación mecánica.

Tabla 3. Variables clínicas y de laboratorio medidas en la admisión al hospital predictoras de eventos adversos serios en el adulto inmunocompetente hospitalizado por neumonía adquirida en la comunidad. Análisis multivariado

\begin{tabular}{|lccccc|}
\hline Admisión a UCI & Coeficiente & Error estándar & OR & IC 95\% & p \\
Enfermedad cardiovascular & 0,4629 & 0,2371 & 1,59 & $1,00-2,53$ & 0,0510 \\
\hline Diabetes mellitus & 0,7147 & 0,2852 & 2,04 & $1,17-3,57$ & 0,0122 \\
EPOC & 0,7366 & 0,3045 & 2,09 & $1,15-3,79$ & 0,0155 \\
Disnea & 0,9299 & 0,3001 & 2,53 & $1,41-4,56$ & 0,0019 \\
Compromiso de conciencia & 0,6816 & 0,2612 & 1,98 & $1,19-3,30$ & 0,0091 \\
Presión arterial diastólica & $-0,0218$ & 0,0077 & 0,97 & $0,96-0,99$ & 0,0049 \\
Frecuencia respiratoria & 0,0428 & 0,0148 & 1,04 & $1,01-1,07$ & 0,0037 \\
Creatininemia & 0,1777 & 0,0670 & 1,19 & $1,05-1,36$ & 0,0080 \\
\hline
\end{tabular}

\begin{tabular}{|lccccc|}
\hline Uso de ventilación mecánica & Coeficiente & Error estándar & OR & IC 95\% & p \\
\hline Frecuencia cardiaca & 0,0349 & 0,0073 & 1,04 & $1,02-1,05$ & 0,0001 \\
\hline Presión arterial diastólica & $-0,0353$ & 0,0103 & 0,97 & $0,95-0,99$ & 0,0006 \\
Temperatura & $-0,4996$ & 0,1561 & 0,61 & $0,45-0,82$ & 0,0014 \\
\hline Nitrógeno ureico sérico & 0,0157 & 0,0079 & 1,02 & $1,01-1,03$ & 0,0479 \\
Potasio sérico & 0,4524 & 0,2139 & 1,57 & $1,03-2,39$ & 0,0345 \\
Neumonía multilobar & 1,3028 & 0,3106 & 3,68 & $2,00-6,76$ & 0,0001 \\
\hline
\end{tabular}




\begin{tabular}{|lccccc|}
\hline Shock séptico & Coeficiente & Error estándar & OR & IC 95\% & p \\
Escalofríos & $-0,9815$ & 0,3979 & 0,37 & $0,17-0,81$ & 0,0136 \\
Compromiso de conciencia & 0,8582 & 0,3164 & 2,36 & $1,27-4,38$ & 0,0067 \\
Frecuencia cardiaca & 0,01390 & 0,0068 & 1,02 & $1,01-1,03$ & 0,0417 \\
Presión arterial diastólica & $-0,0425$ & 0,0106 & 0,96 & $0,94-0,98$ & 0,0001 \\
Nitrógeno ureico sérico & 0,0182 & 0,0071 & 1,02 & $1,01-1,03$ & 0,0102 \\
Glicemia & 0,0044 & 0,0019 & 1,01 & $1,00-1,01$ & 0,0237 \\
\hline
\end{tabular}

\begin{tabular}{|lccccc|}
\hline Complicaciones cardiovasculares & Coeficiente & Error estándar & OR & IC 95\% & p \\
Edad & 0,0362 & 0,0108 & 1,04 & $1,02-1,06$ & 0,0008 \\
Enfermedad cardiovascular & 1,0903 & 0,2637 & 2,98 & $1,77-4,98$ & 0,0001 \\
EPOC & 0,8921 & 0,3174 & 2,44 & $1,31-4,54$ & 0,0049 \\
Sospecha de aspiración & 0,7932 & 0,3885 & 2,21 & $1,03-4,73$ & 0,0412 \\
Frecuencia respiratoria & 0,0448 & 0,0163 & 1,05 & $1,01-1,08$ & 0,0061 \\
Creatininemia & 0,1611 & 0,0577 & 1,18 & $1,05-1,31$ & 0,0052 \\
\hline
\end{tabular}

\begin{tabular}{|lccccc|}
\hline Complicación en el hospital & Coeficiente & Error estándar & OR & IC 95\% & p \\
Comorbilidades & 0,7836 & 0,3047 & 2,19 & $1,21-3,97$ & 0,0101 \\
Fiebre & $-0,4746$ & 0,2319 & 0,62 & $0,39-0,98$ & 0,0407 \\
Disnea & 0,5849 & 0,2618 & 1,79 & $1,07-2,99$ & 0,0255 \\
Presión arterial diastólica & $-0,0218$ & 0,0072 & 0,97 & $0,96-0,99$ & 0,0027 \\
Derrame pleural & 1,0456 & 0,2549 & 2,85 & $1,73-4,69$ & 0,0001 \\
Nitrógeno ureico sérico & 0,0351 & 0,0071 & 1,04 & $1,02-1,05$ & 0,0001 \\
\hline
\end{tabular}

\begin{tabular}{|lccccc|}
\hline Hospitalización prolongada & Coeficiente & Error estándar & OR & IC 95\% & p \\
Comorbilidades & 0,6886 & 0,2547 & 1,99 & $1,21-3,28$ & 0,0069 \\
Disnea & 0,6135 & 0,2213 & 1,85 & $1,20-2,85$ & 0,0056 \\
Compromiso de conciencia & 1,1080 & 0,2600 & 3,03 & $1,82-5,04$ & 0,0001 \\
Presión arterial diastólica & $-0,0175$ & 0,0065 & 0,98 & $0,97-0,99$ & 0,0072 \\
Derrame pleural & 0,7380 & 0,2407 & 2,09 & $1,30-3,35$ & 0,0022 \\
Nitrógeno ureico sérico & 0,0235 & 0,0065 & 1,02 & $1,01-1,03$ & 0,0004 \\
\hline
\end{tabular}

\begin{tabular}{|lccccc|}
\hline Mortalidad a 30 días & Coeficiente & Error estándar & OR & IC 95\% & p \\
Compromiso de conciencia & 1,0177 & 0,3317 & 2,77 & $1,44-5,30$ & 0,0022 \\
Escalofríos & $-1,8911$ & 0,6311 & 0,15 & $0,04-0,52$ & 0,0027 \\
Frecuencia respiratoria & 0,0501 & 0,0202 & 1,05 & $1,01-1,09$ & 0,0134 \\
Temperatura & $-0,3527$ & 0,1753 & 0,70 & $0,50-0,99$ & 0,0442 \\
Nitrógeno ureico sérico & 0,0211 & 0,0076 & 1,02 & $1,01-1,03$ & 0,0058 \\
Albuminemia & $-1,0112$ & 0,3199 & 0,36 & $0,19-0,68$ & 0,0016 \\
\hline
\end{tabular}


Los principales predictores clínicos de riesgo de muerte en el seguimiento a 30 días en el adulto hospitalizado por neumonía adquirida en la comunidad fueron la ausencia de fiebre y escalofríos, compromiso de conciencia, taquipnea, hipoalbuminemia y disfunción renal en la admisión al hospital.

\section{Discusión}

Los principales hallazgos de este estudio fueron: a) La mayoría de los pacientes hospitalizados por neumonía adquirida en la comunidad son adultos mayores con enfermedades cardiovasculares, metabólicas, neurológicas o respiratorias crónicas, y tienen alto riesgo de admisión a UCI, conexión a VM y complicaciones en la evolución en el hospital; b) Las variables clínicas y de laboratorio medidas en la admisión al hospital permiten predecir el riesgo de eventos adversos serios en el adulto hospitalizado por neumonía; c) La presencia de comorbilidades, inestabilidad hemodinámica y disfunción renal en la evaluación inicial se asociaron con la admisión a UCI, riesgo de complicaciones y estadía prolongada en el hospital; d) El uso de ventilación mecánica y shock séptico fue más frecuente en pacientes con inestabilidad hemodinámica y disfunción renal; e) La edad avanzada, enfermedades cardiovasculares y respiratorias crónicas, sospecha de aspiración, taquipnea y disfunción renal se asociaron al riesgo de eventos cardiovasculares en el hospital.

La evaluación clínica sistematizada, incluyendo la radiografía de tórax y los exámenes de laboratorio solicitados en el servicio de urgencia, permiten predecir la evolución del paciente hospitalizado por neumonía adquirida en la comunidad $^{6,25-29}$. Evaluar la gravedad y decidir el lugar de manejo del enfermo (ambulatorio, sala o UCI) es una decisión clínica compleja, forma parte de un proceso dinámico que puede variar en el tiempo, lo cual puede verse dificultado porque los médicos clínicos suelen subestimar, y a veces sobreestimar, la gravedad de la enfermedad ${ }^{20-23}$. Dando respuesta a esta problemática, se han diseñado varios índices pronósticos que tienen como propósito ayudar a los médicos clínicos a evaluar la gravedad de los pacientes con neumonía y estimar el riesgo de complicaciones y eventos adversos serios en la evolución en el hospital ${ }^{6,16-19}$.

En nuestra cohorte, los pacientes con neumonía comunitaria ingresados a la unidad de cuidados intensivos eran principalmente adultos mayores con comorbilidad múltiple, compromiso de conciencia, apremio respiratorio, inestabilidad hemodinámica, insuficiencia respiratoria severa, compromiso radiográfico multilobar y disfunción renal aguda, requiriendo apoyo hemodinámico y conexión a ventilador mecánico en una elevada proporción. Estos criterios de gravedad son mencionados en la guía clínica de la Sociedad Americana de Tórax ${ }^{12}$ y son empleados en la elaboración de los índices predictores de neumonía severa: Índice de gravedad de la neumonía ${ }^{16}$, CURB-65 ${ }^{17}$, SMART-COP $^{18}$ y SCAP ${ }^{19}$. La conexión a ventilación mecánica y el manejo del shock séptico en el paciente con neumonía comunitaria severa son las principales indicaciones de admisión a UCI, lo cual explica que estas variables clínicas permitan predecir estos eventos adversos serios con bastante precisión ${ }^{27-32}$.

La estadía prolongada en el hospital se correlacionó con la enfermedad grave, especialmente en el adulto mayor con comorbilidad múltiple, compromiso de conciencia, dificultad respiratoria, inestabilidad hemodinámica, insuficiencia respiratoria grave, compromiso radiográfico multilobar y derrame pleural, hipoalbuminemia, disfunción renal, necesidad de admisión a UCI y conexión a ventilador mecánico en la admisión al hospital. Además, en esta categoría aumentó significativamente el riesgo de complicaciones en el hospital (OR: 4,45; IC95\%: 3,12-6,35; $\mathrm{p}<0,0001)$.

Los eventos cardiovasculares en el hospital se presentaron principalmente en adultos mayores con enfermedades cardiovasculares o respiratorias crónicas, dificultad respiratoria, taquipnea, insuficiencia respiratoria parcial o global, compromiso radiográfico multilobar, hipoalbuminemia y disfunción renal en la admisión al hospital. La presencia de eventos cardiovasculares se asoció a la admisión a unidad de cuidado intermedio e intensivo por NAC severa, a la conexión a ventilador mecánico por falla respiratoria aguda o inestabilidad hemodinámica y a la estadía prolongada en el hospital.

Los principales predictores de mortalidad en el seguimiento a 30 días fueron la edad avanzada, presencia de comorbilidades, especialmente cardiovascular y neurológica crónica, compromiso de conciencia, hipotensión arterial, taquipnea, ausencia de fiebre, insuficiencia respiratoria severa, compromiso radiográfico multilobar y derrame pleural, hipoalbuminemia y disfunción renal en la admisión al hospital. La mayoría de estos criterios de gravedad están incluidos en el índice de gravedad de la neumonía descrito por Fine y cols. ${ }^{16}$, el cual permite predecir con bastante precisión el riesgo de muerte en el paciente con neumonía; aunque no constituye la herramienta 
ideal para predecir el ingreso a UCI, la conexión a ventilador mecánico y el uso de drogas vasoactivas por shock séptico ${ }^{28-32}$. Por este motivo, se han diseñado nuevas herramientas que incluyen variables clínicas y de laboratorio medidas en la admisión al hospital relacionadas con la gravedad de la infección pulmonar, tales como los criterios de neumonía comunitaria severa propuestos por la Sociedad Americana de Tórax ${ }^{12}$, SMART$\mathrm{COP}^{18}$ y $\mathrm{SCAP}^{19}$, los cuales permiten pesquisar a los pacientes con neumonía comunitaria severa y predecir la admisión a UCI, conexión a VM y el uso de drogas vasoactivas ${ }^{28-30}$.

En las guías clínicas, se recomienda evaluar sistemáticamente la gravedad del paciente con neumonía en la admisión al hospital tomando en consideración la edad, comorbilidades, estado mental, alteración de los signos vitales, presencia de insuficiencia respiratoria aguda o disfunción renal y los hallazgos de la radiografía de tórax, especialmente el compromiso radiográfico multilobar y la presencia de derrame pleural, en la admisión al hospital ${ }^{12-15}$. Esto permite predecir el riesgo de complicaciones y muerte en el hospital, decidir el lugar de manejo, planificar el estudio diagnóstico y tratamiento de la infección pulmonar $^{6,25-32}$. De hecho, varios estudios han demostrado que el retraso en la admisión a UCI del paciente inestable con neumonía se ha asociado a peor pronóstico, aumentando el riesgo de complicaciones y muerte en el hospital ${ }^{33-35}$.

En conclusión, las variables clínicas y de laboratorio medidas en la admisión al hospital permiten predecir el riesgo de complicaciones y muerte en pacientes adultos hospitalizados por neumonía adquirida en la comunidad. No obstante, los diferentes índices pronósticos difieren en su capacidad discriminatoria y precisión para predecir los distintos eventos adversos que se presentan en la evolución en el hospital, lo cual debe ser considerado por los médicos clínicos en la evaluación y manejo de los pacientes hospitalizados por neumonía adquirida en la comunidad ${ }^{16-19,25-32}$.

\section{Bibliografía}

1.- FILE T M JR, MARRIE T J. Burden of communityacquired pneumonia in North American adults. Postgrad Med 2010; 122: 130-41.

2.- ISTURIZ R E, LUNA C M, RAMÍREZ J. Clinical and economic burden of pneumonia among adults in Latin America. Int J Infect Dis 2010; 14: e852-6.

3.- SONG J H, THAMLIKITKUL V, HSUEH P R. Clinical and economic burden of community-acquired pneumonia amongst adults in the Asia-Pacific region. Int $\mathbf{J}$
Antimicrob Agents 2011; 38: 108-17.

4.- WELTE T, TORRES A, NATHWANI D. Clinical and economic burden of community-acquired pneumonia among adults in Europe. Thorax 2012; 67: 71-9.

5.- GBD 2015 Mortality and Causes of Death Collaborators. Global, regional, and national life expectancy, all-cause mortality, and cause-specific mortality for 249 causes of death, 1980-2015: a systematic analysis for the Global Burden of Disease Study 2015. Lancet 2016; 388: 1459-544.

6.- FINE M J, SMITH M A, CARSON C A, MUTHA S S, SANKEY S S, WEISSFELD L A et al. Prognosis and outcomes of patients with community-acquired pneumonia. A meta-analysis. JAMA 1996; 275: 134-41.

7.- SALDÍAS F, DÍAZ O, AGUILERA P. Chapter 5. Clinical diagnosis and severity assessment in immunocompetent adult patients with community-acquired pneumonia. In: Respiratory Diseases and Infection - A New Insight. Edited by Bassam H. Mahboub, InTech, Open Access Publisher. Pages 99-135, 2013.

8.- FREI C R, RESTREPO M I, MORTENSEN E M, BURGESS D S. Impact of guideline-concordant empiric antibiotic therapy in community-acquired pneumonia. Am J Med 2006; 119: 865-71.

9.- REYES S, MARTÍNEZ R, CREMADES M J, MARTÍNEZ E, SOLER J J, MENÉNDEZ R. Empiric treatment in hospitalized community-acquired pneumonia. Impact on mortality, length of stay and re-admission. Respir Med 2007; 101: 1909-15.

10.- MARTÍNEZ R, REYES S, LORENZO M J, MENÉNDEZ R. Impact of guidelines on outcome: the evidence. Semin Respir Crit Care Med 2009; 30: 172-8.

11.- MINISTERIO DE SALUD DE CHILE. Departamento de estadísticas e información de salud Disponible en: http://deis.minsal.cl/index.asp (acceso en mayo de 2017).

12.- MANDELL L A, WUNDERINK R G, ANZUETO A, BARTLETT J G, CAMPBELL G D, DEAN N C et al. Infectious Diseases Society of America/American Thoracic Society Consensus Guidelines on the management of community-acquired pneumonia in adults. Clin Infect Dis 2007; 44 (Suppl 2): S27-S72.

13.- LIM W S, BAUDOUIN S V, GEORGE R C, HILL A T, JAMIESON C, LE JEUNE I et al; Pneumonia Guidelines Committee of the BTS Standards of Care Committee. The British Thoracic Society Guidelines for the management of community-acquired pneumonia in adults: update 2009. Thorax 2009; 64 (Suppl 3): 1-55.

14.- SOCIEDAD CHILENA DE ENFERMEDADES RESPIRATORIAS Y SOCIEDAD CHILENA DE INFECTOLOGÍA. Consenso Nacional 2005: Manejo de la neumonía del adulto adquirida en la comunidad. Rev Chil Enferm Respir 2005; 21: 69-140.

15.- BANTAR C, CURCIO D, JASOVICH A, BAGNULO H, ARANGO A, BAVESTRELLO L et al. Neumonía aguda adquirida en la comunidad en adultos: Actuali- 
zación de los lineamientos para el tratamiento antimicrobiano inicial basado en la evidencia local del Grupo de Trabajo de Sudamérica (ConsenSur II). Rev Chilena Infectol 2010; 27 (Supl 1): 9-38.

16.- FINE M J, AUBLE T E, YEALY D M, HANUSA B H, WEISSFELD L A, SINGER D E et al. A prediction rule to identify low-risk patients with community-acquired pneumonia. N Engl J Med 1997; 336: 243-50.

17.- LIM W S, VAN DER EERDEN M M, LAING R, BOERSMA W G, KARALUS N, TOWN G I et al. Defining community acquired pneumonia severity on presentation to hospital: an international derivation and validation study. Thorax 2003; 58: 377-82.

18.- CHARLES P G, WOLFE R, WHITBY M, FINE M J, FULLER A J, STIRLING R et al; Australian Community-Acquired Pneumonia Study Collaboration. SMARTCOP: a tool for predicting the need for intensive respiratory or vasopressor support in community-acquired pneumonia. Clin Infect Dis 2008; 47: 375-84.

19.- ESPAÑA P P, CAPELASTEGUI A, GORORDO I, ESTEBAN C, ORIBE M, ORTEGA M et al. Development and validation of a clinical prediction rule for severe community-acquired pneumonia. Am J Respir Crit Care Med 2006; 174: 1249-56.

20.- MCMAHON L F JR, WOLFE R A, TEDESCHI P J. Variation in hospital admissions among small areas: a comparison of Maine and Michigan. Med Care 1989; 27: 623-31.

21.- NEILL A M, MARTIN I R, WEIR R, ANDERSON $\mathrm{R}$, CHERESHSKY A, EPTON M J et al. Communityacquired pneumonia: aetiology and usefulness of severity criteria on admission. Thorax 1996; 51: 1010-6.

22.- FINE M J, HOUGH L J, MEDSGER A R, LI Y H, RICCI E M, SINGER D E et al. The hospital admission decision for patients with community-acquired pneumonia: results from the pneumonia Patient Outcomes Research Team cohort study. Arch Intern Med 1997; 157: 36-44.

23.- MARRIE T J, LAU C Y, WHEELER S L, WONG C J, VANDERVOORT M K, FEAGAN B G. A controlled trial of a critical pathway for treatment of communityacquired pneumonia. CAPITAL Study Investigators. Community-Acquired Pneumonia Intervention Trial Assessing Levofloxacin. JAMA 2000; 283: 749-55.

24.- FANG G D, FINE M, ORLOFF J, ARISUMI D, YU $\mathrm{V}$ L, KAPOOR W et al. New emerging etiologies for community-acquired pneumonia with implications for therapy. A prospective multicenter study of 359 cases. Medicine (Baltimore) 1990; 69: 307-16.

25.- CHALMERS J D, SINGANAYAGAM A, AKRAM A R, MANDAL P, SHORT P M, CHOUDHURY G et al. Severity assessment tools for predicting mortality in hospitalised patients with community-acquired pneumonia. Systematic review and meta-analysis. Thorax 2010; 65: 878-83.

26.- LOKE Y K, KWOK C S, NIRUBAN A, MYINT P K.
Value of severity scales in predicting mortality from community-acquired pneumonia: systematic review and meta-analysis. Thorax 2010; 65: 884-90.

27.- SINGANAYAGAM A, CHALMERS J D, HILL A T. Severity assessment in community-acquired pneumonia: a review. QJM 2009; 102: 379-88.

28.- MARTI C, GARÍN N, GROSGURIN O, PONCET A, COMBESCURE C, CARBALLO $S$ et al. Prediction of severe community-acquired pneumonia: a systematic review and meta-analysis. Crit Care 2012; 16: R141.

29.- CHALMERS J D, MANDAL P, SINGANAYAGAM A, AKRAM A R, CHOUDHURY G, SHORT P M et al. Severity assessment tools to guide ICU admission in community-acquired pneumonia: systematic review and meta-analysis. Intensive Care Med 2011; 37: 1409-20.

30.- YANDIOLA P P E, CAPELASTEGUI A, QUINTANA J, DIEZ R, GORORDO I, BILBAO A et al. Prospective comparison of severity scores for predicting clinically relevant outcomes for patients hospitalized with community-acquired pneumonia. Chest 2009; 135: 1572-9.

31.- SALDÍAS F, DÍAZ O. Severity scores for predicting clinically relevant outcomes for immunocompetent adult patients hospitalized with community-acquired pneumococcal pneumonia. Rev Chilena Infectol 2011; 28: 303-9.

32.- BUISING K L, THURSKY K A, BLACK J F, MACGREGOR L, STREET A C, KENNEDY M P et al. A prospective comparison of severity scores for identifying patients with severe community acquired pneumonia: reconsidering what is meant by severe pneumonia. Thorax 2006; 61: 419-24.

33.- CHALFIN D B, TRZECIAK S, LIKOUREZOS A, BAUMANN B M, DELLINGER R P; DELAY-ED study group. Impact of delayed transfer of critically ill patients from the emergency department to the intensive care unit. Crit Care Med 2007; 35: 1477-83.

34.- RESTREPO M I, MORTENSEN E M, VELEZ J A, FREI C, ANZUETO A. A comparative study of community-acquired pneumonia patients admitted to the ward and the ICU. Chest 2008; 133: 610-7.

35.- RENAUD B, SANTIN A, COMA E, CAMUS N, VAN PELT D, HAYON J et al. Association between timing of intensive care unit admission and outcomes for emergency department patients with community-acquired pneumonia. Crit Care Med 2009;3 7: 2867-74.

Correspondencia a:

Dr. Fernando Saldías Peñafiel

Departamento de Enfermedades Respiratorias División de Medicina - Facultad de Medicina Pontificia Universidad Católica de Chile Diagonal Paraguay 362, Santiago, Chile. Email: fsaldias@med.puc.cl 